\title{
We should replace conventional mental health law with capacity-based law
}

\author{
George Szmukler/Brendan D. Kelly
}

\section{Summary}

As general medicine moves away from 'paternalism' and places an increasing emphasis on patient choice and autonomy, George Szmukler and Brendan D. Kelly debate whether conventional mental health legislation should be replaced with a model that focuses on the person's decisionmaking capabilities.

\section{Declaration of interest}

G.S.: None/B.D.K.: None.

\section{Copyright and usage}

(c) The Royal College of Psychiatrists 2016.

\section{For}

The principles governing detention and involuntary treatment in mental health law have remained fundamentally unchanged for around two centuries. These principles reflect damaging stereotypes of people with mental illness. There are two common and deeply entrenched criteria for compulsion: first, the presence of a 'mental disorder'; and second, a risk of harm to the person with the disorder or to others. Such 'disorder + risk' civil commitment legislation now needs to be replaced. The reason for this is a decisive one - the current legislation discriminates against people with mental illness.

\section{How mental health law discriminates}

The discrimination is clear when we compare this 'disorder + risk' schema with involuntary treatment in the rest of medicine. In contrast to the stasis in civil commitment law, general medicine in the past 40 years has seen a revolution in the respect accorded to patient self-determination (or 'autonomy'), and a parallel decline in 'paternalism'. This has taken place through the development of the doctrine of 'informed consent'. It is only when a person lacks the capacity to give such consent that the possibility of non-consensual or involuntary treatment enters the frame. (Non-coercion and adequate disclosure of relevant information are also necessary.) With a lack of capacity, there is a further requirement - treatment must be in the person's 'best interests'. We then accept that patients with 'physical' disorders, provided they have decision-making capacity, can make decisions that may be seriously detrimental to their health, even if these decisions are life-threatening.

By contrast, under conventional mental health legislation, decision-making capacity plays little or no part in the initiation of detention or involuntary psychiatric treatment. (In some jurisdictions - for example, Germany and some states in the USA - whereas detention is based on 'disorder + risk', involuntary treatment requires some form of capacity evaluation. How valid consent can be under the threat of detention is an important question here.) In the majority of jurisdictions, 'disorder + risk' is essentially the formula for both detention and involuntary treatment. There is thus a failure to accord equal respect for autonomy or self-determination to all categories of patient. For a person with a diagnosis of a mental disorder who rejects treatment, key abilities underlying decision-making do not demand special attention as they do for general patients - for example, the person's ability to understand important information about their illness and treatment, to appreciate the relevance of that information to their predicament, and to reason with that information in the light of the values and life goals that are important to them. Nor does the question arise of whether the proposed treatment is in the best interests of the person - from the perspective of the person, not of the clinical team. For example, what would the person have chosen in the current circumstances if they had retained capacity?

There is an underlying assumption in mental health legislation that 'mental disorder' necessarily entails mental incapacity, and that the wishes and preferences of a person with a 'disordered mind' are not a reliable guide to where their best interests lie. However, research has shown that even among the very ill - those admitted to acute psychiatric wards - around 50\% retain capacity. ${ }^{1}$ The stereotype of a person with mental disorder as incompetent to decide is embodied in legislation that applies uniquely to those with such a disorder. It thus discriminates unfairly against those persons.

\section{Treatment for the protection of others}

There is a second form of discrimination. People with mental disorders are almost uniquely liable to detention (usually in hospital) because they are assessed as presenting a risk of harm to others, without having actually committed an offence (or being strongly suspected of having committed one). This constitutes a form of preventive detention.

At any one time in the population, there is a group of people who represent a significant risk to others. A small proportion of people with a mental disorder will fall into this group. They represent only a tiny percentage of the total number of risky people in the population, the vast majority of whom will not have a mental disorder. Nevertheless, civil commitment law permits the detention on the basis of risk alone only of those with mental disorder - not the much larger body of the risky group without such disorder. How can this be justified? Equals are being treated unequally. There is no evidence that risk is easier to assess in those with mental disorder, nor that violence is more predictable in this group. Could 'treatability' be a justification? Extremely lengthy stays in secure hospitals suggest this is not so. And it is possible - indeed, highly probable - that psychosocial interventions such as controlled drinking or anger management programmes for risky persons without mental disorder would have a greater impact on violence in our community. After all, those with a mental illness account for only a small percentage of serious violence in our society. ${ }^{2}$ 
One must conclude that the 'protection of others' criterion is discriminatory. If preventive detention is to be allowed for those with a mental disorder solely on account of the risk posed to others, then to avoid discrimination it should be so for all of us. This would amount to a generic dangerousness provision that many would find unacceptable. But the principle of nondiscrimination requires that we have laws applicable either to all of us, or to none of us - including those with mental disorder.

Thus, those with mental disorder are denied the protections from preventive detention enjoyed by the rest of us. Such a provision reinforces the damaging stereotype that the mentally ill are inherently dangerous. Furthermore, the uncertain boundary around the notion of 'mental disorder' and our poor ability to accurately assess risk offer a less legally demanding back door to the detention of people considered to pose a threat to the social order. The Soviet Union in the 1960s-1970s was a stark example, but, nearer to home, the Dangerous and Severe Personality Disorder programme was arguably another.

\section{The solution to the discrimination}

To eliminate the discrimination there are two possibilities. First, we could adopt mental health-type law for all medical conditions, or second, we could adopt a 'capacity + best interests' schema for mental disorders. I doubt that many of us would opt for the 'doctor knows best' approach and patient disempowerment entailed in the first option. The second option is thus preferable. (Given the fundamental values in our society, it is also hard to come up with a credible alternative to a schema that supports choice and self-determination.)

Opting for a 'capacity + best interests' framework in mental healthcare leads to a further step in the argument. If the framework is to be the same as for non-psychiatric disorders, separate mental health law becomes redundant. Hence the proposal for a 'fusion' law' ${ }^{3-5}$ - a generic law applicable across all medical specialities (as well as in social care), in all settings, where a person has a difficulty in making a serious treatment decision. Involuntary treatment would only be permitted when two conditions were met: first, that the objecting person has an impairment of decision-making capacity - resulting from any cause - and second, that treatment is in the person's best interests. The fusion approach builds on the strengths of the two existing legal regimes. The strength of capacity-based legislation - giving weight to autonomy - is counterbalanced by a number of weaknesses, including a lack of sufficient attention to detention and the use of force. However, these are the areas in which civil commitment schemes are strong: these measures are clearly authorised and regulated. Indeed, the lack of clarity in these areas in capacity-based legislation may engender problems concerning patients with physical disorders who object to treatment. Clinicians may be reluctant to use force unless they can rely on clear statutory authority. A problem with separate mental health and capacity regimes is the lack of clarity about which should apply when patients meet the criteria of both, or when both may be required for the same person because they object to treatment of a mental disorder and an unrelated physical disorder at the same time.

\section{Capacity-based law}

The Mental Capacity Act 2005 in England and Wales has taught us much about capacity-based law. Although there have been some problems with implementation, as is to be expected with new law, the Act is generally held in high regard. ${ }^{6}$ I know of no calls for it to be repealed. Capacity can be as reliably assessed in psychiatry as in general medicine. ${ }^{1,7}$ I see no reason to believe that principles along the lines of the Mental Capacity Act cannot be applied in mental healthcare. Such legislation has been drafted. ${ }^{4,5,8}$ Measures can be devised - for example, independent advocacy, the involvement of those who know the person well and second opinions - to ensure that patients are not regarded as lacking capacity simply because they disagree with their doctors.

The concepts of 'capacity' and 'best interests' have advanced over the years, particularly in relation to the assessment of the 'use' and 'weigh' (or 'appreciation' and 'reasoning') elements of the former, and the special regard to be given to the person's wishes, beliefs and values in the assessment of the latter. There is also an approach to engagement with the important UN Convention on the Rights of Persons with Disabilities 2006 (CRPD). The Convention, now ratified by 164 countries, aims as does the generic fusion proposal - to eliminate discrimination towards persons with disabilities (including mental health disabilities). The key concepts of 'will' and 'preferences' in the CRPD, it can be argued, are reconcilable with capacity-based law, ${ }^{9}$ but certainly not with conventional mental health law. The fusion law offers the most credible instantiation of those principles in practice. ${ }^{10}$ Support for decision-making is a crucial component. Advance directives may assume an important role in the expression of patients' will and preferences when ill.

In summary, the moral case for abandoning conventional mental health law is decisive. The discrimination such law entails cannot be supported. The solution for eliminating that discrimination is a decision-making capability mental health law - or, better still, a decision-making capability generic law. A number of jurisdictions (including Tasmania and Western Australia), recognising the unfairness, have recently enacted the former, and a similar mental health bill is currently somewhere in the legislative process in India. Northern Ireland has taken the groundbreaking step of enacting the latter.

George Szmukler

\section{Against}

In 1684, Nathaniel Lee, an exuberant Restoration playwright, was detained at Bethlem: 'They called me mad, I called them mad, and damn them, they outvoted me. ${ }^{11}$ Under a 'fusion law' or capacitybased legislation, Lee, if detained, would exclaim: 'They called me lacking in decision-making capability, I called them lacking in decision-making capability, and damn them, they outvoted me'. Given that neither exclamation is especially desirable, is the latter preferable to the former?

Given the challenges and imperfections of current mental health legislation in most jurisdictions, ${ }^{12}$ I would dearly love to agree with the merits of a fusion law. ${ }^{3-5,13}$ Sadly, however, there are simply too many problems with this idea to see it as significantly more than a shift in language that would have the unintended consequences of diminishing compliance with international human rights standards and worsening the position of the mentally ill.

But first, some specific points. Professor Szmukler writes that mental health legislation is discriminatory on the grounds that in general medicine, it is only when a person lacks mental capacity to give consent 'that the possibility of non-consensual or involuntary treatment enters the frame'. The disorder + risk paradigm is not unique to mental disorders. Physical disorders occasionally create situations of similar risk to others, and most legislatures permit involuntary detention and/or treatment of persons with, for example, infectious tuberculosis if they present a substantial risk to the public, even though they possess full mental capacity. Although these occurrences are rare, the principle is the same as with mental disorder: disorder + risk can result in detention and/or treatment. 
Professor Szmukler is correct, however, to write that mental health legislation is discriminatory, at least to the extent that it treats some people with mental disorder differently to people without mental disorder. That is its purpose: to recognise that mental disorder occasionally creates situations for which dedicated legislative measures and protections are necessary, even to the point of mandating involuntary treatment when a person with full mental capacity fulfils certain criteria (for example, if they have mental disorder which presents substantial risk to others). 'Treatability' is a key requirement here, and the existence of a small minority of treatment-resistant cases in secure hospitals does not obviate the fact that most mental disorder is treatable.

In any case, even if we are to accept the use of the term 'discrimination' in a negative sense in the context of legislation based on disorder + risk, then a law mandating substitute decision-making on the basis of impaired decision-making capability would be equally discriminatory, albeit that it would 'discriminate' on the basis of decision-making capability rather than mental disorder + risk. Plus ça change.

Professor Szmukler makes an interesting reference to political abuse of psychiatry in the 'Soviet Union of the 1960s-1970s', and this is an important point: it is critical that legislation prevents abuse. Unfortunately, assessments of decision-making capability are no less vulnerable to manipulation or misuse than assessments of mental disorder or risk; indeed, they are probably more vulnerable to such machinations. The best protection against abuse is surely to create legislation that accords better with international human rights standards. Unfortunately, it is here that the fusion proposal is most notably deficient.

The CRPD ${ }^{14}$ is deeply challenging to psychiatry. ${ }^{15}$ It defines 'persons with disabilities' to 'include those who have long-term physical, mental, intellectual or sensory impairments which in interaction with various barriers may hinder their full and effective participation in society on an equal basis with others' (Article 1). ${ }^{14}$ This definition is likely to include at least some people with mental disorder (especially those who receive involuntary care) with the result that virtually all mental health legislation violates the CRPD requirement 'that the existence of a disability shall in no case justify a deprivation of liberty' (Article 14). ${ }^{14,15}$

Capacity-based legislation, however, would not only violate Article 14, but would also be grossly inconsistent with the position of the Committee on the Rights of Persons with Disabilities, appointed by the UN under the CRPD, which explicitly rejects the use of 'mental capacity' in any form (let alone placing it at the heart of a new paradigm):

'Mental capacity is not, as is commonly presented, an objective, scientific and naturally occurring phenomenon. Mental capacity is contingent on social and politica contexts, as are the disciplines, professions and practices which play a dominant role in assessing mental capacity'.16

The Committee notes that the 'functional approach' to assessing mental capacity (as in the Mental Capacity Act 2005) is 'often based on whether a person can understand the nature and consequences of a decision and/or whether he or she can use or weigh the relevant information', and concludes that 'this approach is flawed for two key reasons':

'(a) it is discriminatorily applied to people with disabilities; and (b) it presumes to be able to accurately assess the inner-workings of the human mind and, when the person does not pass the assessment, it then denies him or her a core human right - the right to equal recognition before the law. In all of those approaches, a person's disability and/or decision-making skills are taken as legitimate grounds for denying his or her legal capacity and lowering his or her status as a person before the law. Article 12 does not permit such discriminatory denial of legal capacity . . .

The Committee concludes that 'the provision of support to exercise legal capacity should not hinge on mental capacity assessments; new, non-discriminatory indicators of support needs are required in the provision of support to exercise legal capacity. ${ }^{16}$ Dawson \& Szmukler have been particularly clear that that their proposal involves substitute decision-making on the basis of the loss of ability to make decisions, ${ }^{3}$ and the fusion proposal is thus fundamentally inconsistent with the Committee's position on capacity assessments.

The precise formulation proposed by Dawson \& Szmukler centres on 'a person's ability to understand and retain relevant information, to use or weigh that information in the decisionmaking process, and to communicate the decisions made.' If there is a difference between the absence of an 'ability' (even if based on function rather than status) and a 'disability' (as conceptualised by the UN), it is a vanishingly subtle one. If the CRPD regards a person with impairment resulting from long-term mental disorder as a person with a 'disability', then it will surely regard a person with impairment from a long-term loss of decision-making ability in precisely the same way.

The fusion proposal is thus an explicitly disability-based mechanism for substitute decision-making, and thus it is even more inconsistent with the CRPD than current mental health legislation. To compound matters, the Committee on the Rights of Persons with Disabilities also explicitly rejects the idea of 'substitute decision-making', which lies at the heart of the fusion proposal:

'States parties' obligation to replace substitute decision-making regimes by supported decision-making requires both the abolition of substitute decision-making regimes and the development of supported decision-making alternatives. The development of supported decision-making systems in parallel with the maintenance of substitute decision-making regimes is not sufficient to comply with article 12 of the Convention'. ${ }^{16}$

There are many other problems with the fusion proposal. It includes a somewhat re-engineered version of 'best interests, ${ }^{4,5}$ a concept that the CRPD conspicuously eschews entirely (except in relation to children) in favour of emphasising the 'will and preferences of the person' (Article 12). ${ }^{14}$ The problems relating to risk are so stark as to be undeniable. Dawson \& Szmukler acknowledge this inadequacy of 'pure incapacity principles', noting that exceptions to their proposed paradigm would be needed for certain patients in order 'to reduce the risk of harm to others. ${ }^{3}$ What is being suggested, then, is not a capacity-based system for everyone, but a capacity-based system for some people and not for others. For the latter group, which will include certain forensic patients, it seems that another set of criteria will be required, based on traditional criteria of 'serious mental impairment or disturbance' and assessment of risk. ${ }^{4,5}$

There are yet more problems. ${ }^{17}$ Allowing people to develop serious mental disorder to the point of losing mental capacity before involuntary care can be considered seems likely to delay treatment (unless the mental capacity threshold is set so low as to be meaningless); delaying treatment and requiring loss of mental capacity for involuntary care would surely increase the possibility of mentally ill people entering the criminal justice system (despite the fact that prisons are demonstrably toxic for mentally ill people); and treating mental capacity as a binary concept is an excessive simplification: many patients have partial mental capacity which can fluctuate within the hour. This is an acknowledged problem with the fusion proposal, ${ }^{3}$ but no convincing solution has emerged. How would a capacity-based paradigm provide consistent, reliable care in such a circumstance? What about partial mental capacity?

The idea of capacity-based legislation has considerable history. ${ }^{18}$ In 1999, the Richardson Committee, charged with advising the government on new mental health legislation, considered the matter carefully and found that only a 'small minority' believed that 'a mental health act should authorise treatment in the absence of consent only for those who lack capacity' or that 'if a person with a mental disorder who refused 
treatment was thought to pose a serious risk to others then he or she should be dealt with through the criminal justice system, not through a health provision. ${ }^{19}$

There was 'a much larger body of opinion which was prepared to accept the overriding of a capable refusal in a health provision on grounds of public safety in certain circumstances'. The Committee inclined towards the latter view:

'The reasons given were in part pragmatic and in part driven by principle. Essentially most of those who commented accepted that the safety of the public must be allowed to outweigh individual autonomy where the risk is sufficiently great and, if the risk is related to the presence of a mental disorder for which a health intervention of likely benefit to the individual is available, then it is appropriate that such intervention should be authorised as part of a health provision. Mental disorder unlike most physical health problems may occasionally have wider consequences for the individual's family and carer, and very occasionally for unconnected members of the public affected by the individual's behaviour, acts and omissions. The Committee supports this reasoning . . .'19

This emphatic rejection of a capacity-based system did not emerge from abstract legal thought or intellectual theorising; the Committee's report was based on hundreds of submissions and consultation with hundreds of organisations and individuals, including 'service users, carers and voluntary workers, social services senior managers and approved social workers, consultant psychiatrists, general practitioners, service managers, probation and police officers, and nurses. ${ }^{19}$

It is easy to get mental health legislation wrong. As a result, there needs to be strong prima facie evidence that any proposed change represents a genuine advance that will truly promote the interests and autonomy of the mentally ill. The onus of proof lies on the proposers of change to demonstrate that their suggested legislation is more protective of rights, more supportive of treatment and more compassionate than the current arrangement. This is not the case with the fusion proposal, which seeks simply to replace one imperfect paradigm with an even more imperfect one.

Brendan D. Kelly

\section{For: rebuttal}

Professor Kelly's spirited defence of the current legislation is far from convincing.

\section{Comparison with infectious disease}

Legislation permitting the detention of persons with infectious disease (which was used 7 times in England in 2013-2014, compared with over 50000 mental illness detentions) is not discriminatory. All persons presenting an equal risk of infecting others are equally liable to detention; there is no subcategory of persons singled out, a priori, as uniquely liable to detention. This is quite different to the situation regarding people presenting an equal risk of violence to others; only one subcategory is singled out as liable to preventive detention - those with a mental disorder. Therein lies the discrimination.

\section{Compliance with the CRPD}

It is astonishing to read that the fusion proposal is 'even more inconsistent with the CRPD than current mental health legislation'. A disability ('mental disorder') is there in black and white on the face of 'disorder + risk' legislation and is thus directly discriminatory. Furthermore, such legislation does not respect, in any sense, the autonomy of patients, nor does it demand any attention be given to their wishes and feelings (or 'will and preferences'). Is there a more uncompromising form of 'substitute decision-making'?

The fusion framework, gaining from recent work on capacity and best interests - unfortunately ignored by Professor Kelly - is as close as we are likely to get to the CRPD ideal in practice. $^{10}$
Such law must be generic, covering all persons who have a serious problem with making a treatment decision, whatever the cause of that problem. If an impairment of decision-making ability is itself a 'disability' under the CRPD, then those with concussion or postoperative confusion could never be treated non-consensually. That cannot be right. Yes, the fusion law is based on impaired decisionmaking capability (whether the person has a pre-existing disability as defined by the CRPD or not) and best interests. But there are different versions of the meanings of these terms. The CRPD Committee has criticised one. ${ }^{16}$ There is no space for detail here, but there are accounts available of how those criteria can be reformulated, indeed clarified, to encompass the person's 'will and preferences', which is the CRPD touchstone. Recent work on decision-making capability has focused on the special regard that is to be given to the person's deeply held beliefs and values - or, in the Committee's words, the 'best interpretation' of 'will and preferences' 9,10,20 (see also Kings College Hospital NHS Foundation Trust $v$ C \& Anor).

Although people with mental illness might more often fall under a fusion law than those without, disproportionate effect does not automatically equal indirect discrimination. ${ }^{9}$

\section{Public protection}

A fusion law will not compromise public protection. ${ }^{4,5}$ There are only two instances in which Dawson and I suggested that a person with capacity might be treated involuntarily: 'unfitness to plead' and 'not guilty by reason of insanity'. The problem is not solely with mental health law. Even if the person has committed a serious offence, in many jurisdictions gaol is not an option as no conviction is possible. What should then be done if the person is deemed to represent a serious risk of harm to others, but retains decision-making capability and refuses voluntary treatment? Until a 'third way' is found to manage such offenders - perhaps a form of supervision with 'teeth' - we reluctantly accepted that under specified conditions (for example, where an effective treatment to reduce risk is available) detention in a hospital might be justified.

\section{Other points}

I think most would disagree that a capacity-based law would delay initiating treatment. One often sees patients who are clearly ill and unable to make a treatment decision, and who act in ways seriously jeopardising their most valued life projects. How often does one hear that a person has not yet done anything 'risky enough' to meet the criterion for legal detention? ${ }^{21}$

Although the Richardson Committee did for the most part support a 'capacity' criterion, where there was a 'serious' risk it proposed that, if effective, involuntary treatment of a patient with capacity was acceptable. There was a moral panic about 'dangerous' mental patients at the time and a 'pure' capacity law was a political non-starter. In Northern Ireland, 10 years on, such law had become acceptable - indeed, desirable - and received wide stakeholder support.

If a state does not respect law, abuses of psychiatry may occur whatever the law says. However, if a person's beliefs and values must be evaluated according to a law that is not just for the mentally ill - instead of whether they meet some blurred diagnostic criteria - dissent rather than disease is perhaps more likely to be the conclusion. Thus, more exacting legal requirements for detention will apply than for 'backdoor' mental hospitalisation.

As for 'fluctuating' capacity: decision-making capability obviously needs to be sufficiently sustained for the person to be able to make a valid decision. 'Hourly' fluctuations may occur in acute organic states, but rarely in psychosis. If fluctuations 
characterise the course of a mental illness, isn't this a prime indication for an advance directive made when the person has capacity?

George Szmukler

\section{Against: rebuttal}

I am very grateful to Professor Szmukler for his response. I am especially pleased that my arguments remain entirely valid.

It remains the case that legislation permitting compulsory treatment of infectious diseases uses a disorder + risk paradigm, as people who present a public risk due to infectious diseases are treated differently to those presenting a public risk for other reasons (for example, habitual criminality); mental health legislation is therefore not unique in this regard. It also remains the case that there will need to be exceptions to the fusion proposal for certain people with mental disorder who present high risk; these exceptions rest uneasily with the idea that the fusion proposal is non-discriminatory or that it addresses risk adequately.

In brief response to other points: most people would surely agree that waiting for someone to lose capacity could delay treatment; the Richardson Committee was notably emphatic about retaining the possibility to override a capacitous refusal of treatment in certain circumstances; and the merits of advance directives are not exclusive to the fusion proposal: advance directives are already in place in many jurisdictions.

In the end, however, it is still the UN human rights standards that highlight the greatest flaws in the fusion proposal. Impaired decision-making capability is a 'disability' under the CRPD every bit as much as 'mental disorder', if not more so. This makes the fusion proposal (as well as current legislation) fundamentally inconsistent with Article 14. ${ }^{14}$

There are additional human rights problems with the fusion proposal. The Committee on the Rights of Persons with Disabilities explicitly rejects the use of 'mental capacity' in any form as the basis for legislation governing substitute decisionmaking. ${ }^{16}$ The fusion proposal not only retains mental capacity at the heart of its paradigm, but seeks to extend its remit into areas currently covered by mental health legislation

This is a pity. I would dearly love to believe in the fusion proposal. My arguments were not, as suggested, a 'defence of current legislation', which is clearly flawed. I was, rather, exploring the idea that new proposals must offer compelling advantages over the existing situation if they are to be tried, as there are serious issues at stake. The fusion proposal fails to meet this requirement.

Given the side I was accorded in this debate, it is perhaps surprising that I am sad to see the fusion proposal so comprehensively diminished. But like many psychiatrists, I long for a paradigm shift in mental health legislation that will improve provision of care and promote autonomy and dignity. Unfortunately, the fusion proposal is not that paradigm shift.

But all is not lost with the fusion proposal, for two reasons. First, there is always the possibility (rarely articulated in debates) that I might be wrong in concluding that the fusion proposal is not a good idea. When I reflect on the matter, I don't think that I am wrong. But, then, that is precisely what being wrong is: when you're wrong, you don't think you're wrong. Second, maybe, just maybe - despite the conceptual difficulties, clear human rights problems and lack of evidence - capacity-based mental health legislation will simply work. It is by no means uncommon for ideas to work out well in practice despite many theoretical reasons to believe that they will not. Life is funny that way: outcomes can be unpredictable, paradoxical and counterintuitive.

Happily, we do not have to wait long to find out. Capacitybased mental health legislation is being introduced in Northern Ireland at present. And although Professor Szmukler has not convinced me of the merits of this approach, his thoughtful, robust and deeply compassionate advocacy for this paradigm have convinced me that an experiment is merited and that the resultant data should be examined with care.

To paraphrase my childhood hero, Sherlock Holmes: it is a capital mistake to theorise too much before one has the data. ${ }^{22,23}$

Brendan D. Kelly

For: George Szmukler, MB, BS, MD, FRCPsych, FKC, Institute of Psychiatry,

For: George Szmukler, $\mathrm{MB}, \mathrm{BS}, \mathrm{MD}, \mathrm{FRCPSych,}, \mathrm{FKC}$, Institute of Psychiatry,
Psychology and Neuroscience, King's College London, De Crespigny Park, Denmark Hill, London SE5 8AF, UK. Email: george.szmukler@kcl.ac.uk.

Against: Brendan D. Kelly, MB BCh BAO, MA MSC MA, MD PhD DGov PhD, FRCPsych FRCPI, Department of Psychiatry, Trinity College Dublin, Trinity Centre for Health Sciences, Tallaght Hospital, Dublin 24, Ireland. Email: brendan.kelly@tcd.ie

\section{References}

1 Okai D, Owen G, McGuire H, Singh S, Churchill R, Hotopf M. Mental capacity in psychiatric patients: systematic review. Br J Psychiatry 2007; 191: 291-7.

2 Flynn S, Rodway C, Appleby L, Shaw J. Serious violence by people with mental illness: national clinical survey. J Interpers. Violence 2014; 29: 1438-58.

3 Dawson J, Szmukler G. Fusion of mental health and incapacity legislation. Br J Psychiatry 2006; 188: 504-9.

4 Szmukler G, Daw R, Dawson J. A model law fusing incapacity and mental health legislation. J Ment Health Law 2010; 20: 9-22.

5 Szmukler G, Daw R, Dawson J. Outline of the model law. J Ment Health Law 2010; 20: 99-122.

6 House of Lords. Mental Capacity Act 2005: Post-Legislative Scrutiny. Report of Select Committee. TSO (The Stationery Office), 2014.

7 Cairns R, Maddock C, Buchanan A, David AS, Hayward P, Richardson G, et al. Reliability of mental capacity assessments in psychiatric in-patients. Br J Psychiatry 2005; 187: 372-8.

8 Northern Ireland Assembly. Mental Capacity Bill. NI Assembly, 2016 (http:// www.niassembly.gov.uk/globalassets/documents/legislation/bills/executivebills/session-2014-2015/mental-capacity/mental-capacity-bill-as-amendedat-cs.pdf).

9 Martin W, Michalowski S, Jutten T, Burch W. Achieving CRPD Compliance: An Esssex Autonomy Project Position Paper. University of Essex, 2015

10 Szmukler G, Bach M. Mental health disabilities and human rights protections. Glob Ment Health 2015; 2: e20.

11 Porter R. Madness: A Brief History. Oxford University Press, 2002.

12 Kelly BD. Mental Illness, Human Rights and the Law. RCPsych Publications, 2016.

13 Szmukler G, Daw R, Callard F. Mental health law and the UN Convention on the rights of persons with disabilities. Int J Law Psychiatry 2014; 37: 245-52.

14 United Nations. Convention on the Rights of Persons with Disabilities. United Nations, 2006.

15 Kelly BD. An end to psychiatric detention? Implications of the United Nations Convention on the Rights of Persons with Disabilities. Br J Psychiatry 2014; 204: $174-5$.

16 Committee on the Rights of Persons with Disabilities. General Comment No. 1. United Nations, 2014

17 Burns T. Mental illness is different and ignoring its differences profits nobody. J Ment Health Law 2010; 20: 34-9.

18 Holland A. The model law of Szmukler, Dawson and Daw - the next stage of a long campaign? J Ment Health Law 2010; 20: 63-70.

19 Expert Committee. Review of the Mental Health Act 1983. Department of Health, 1999.

20 Banner N, Szmukler G. 'Radical Interpretation' and the assessment of decision-making capacity. J Appl Philos 2014: 30: 379-94.

21 Large M, Nielssen O, Ryan C, Hayes R. Mental health laws that require dangerousness for involuntary admission may delay the initial treatment of schizophrenia. Soc Psychiatry Psychiatr Epidemiol 2008: 43: 251-6.

22 Doyle AC. A Study in Scarlet. Ward Lock \& Co., 1887.

23 Doyle AC. The Adventures of Sherlock Holmes. George Newnes, 1892.

\section{Case}

Kings College Hospital NHS Foundation Trust $v$ C \& Anor [2015] EWCOP 80 (http://www.bailii.org/ew/cases/EWCOP/2015/80.html). 